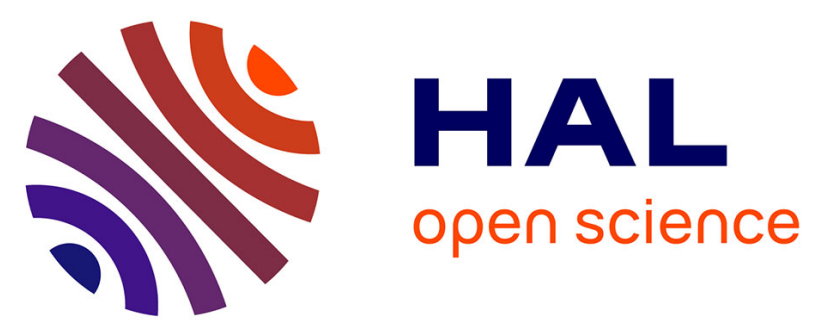

\title{
Power Conversion Efficiency Improvement of Planar Organic Photovoltaic Cells Using an Original Hybrid Electron-Transporting Layer
}

Linda Cattin, Guy Louarn, Ludovic Arzel, Nicolas Stephant, Mustapha

Morsli, Jean-Christian Bernede

\section{To cite this version:}

Linda Cattin, Guy Louarn, Ludovic Arzel, Nicolas Stephant, Mustapha Morsli, et al.. Power Conversion Efficiency Improvement of Planar Organic Photovoltaic Cells Using an Original Hybrid ElectronTransporting Layer. ACS Omega, 2021, 6 (10), pp.6614-6622. 10.1021/acsomega.0c05259 . hal03188562

\section{HAL Id: hal-03188562 https://hal.science/hal-03188562}

Submitted on 18 Nov 2021

HAL is a multi-disciplinary open access archive for the deposit and dissemination of scientific research documents, whether they are published or not. The documents may come from teaching and research institutions in France or abroad, or from public or private research centers.
L'archive ouverte pluridisciplinaire HAL, est destinée au dépôt et à la diffusion de documents scientifiques de niveau recherche, publiés ou non, émanant des établissements d'enseignement et de recherche français ou étrangers, des laboratoires publics ou privés. 


\section{Power Conversion Efficiency Improvement of Planar Organic Photovoltaic Cells Using an Original Hybrid Electron-Transporting Layer}

Linda Cattin,* Guy Louarn, Ludovic Arzel, Nicolas Stephant, Mustapha Morsli, and Jean Christian Bernède

Cite This: ACS Omega 2021, 6, 6614-6622

Read Online

ABSTRACT: In organic photovoltaic (OPV) cells, besides the organic active layer, the electron-transporting layer (ETL) has a primordial role in transporting electrons and blocking holes. In planar heterojunction-OPVs (PHJ-OPVs), the ETL is called the exciton blocking layer (EBL). The optimum thickness of the EBL is $9 \mathrm{~nm}$. However, in the case of inverted OPVs, such thickness is too high to permit efficient electron collection, due to the fact that there is no possibility of metal diffusion in the EBL during the top metal electrode deposition. In the present work, we show that the introduction of a thin potassium layer between the indium tin oxide (ITO) cathode and the EBL increases dramatically the

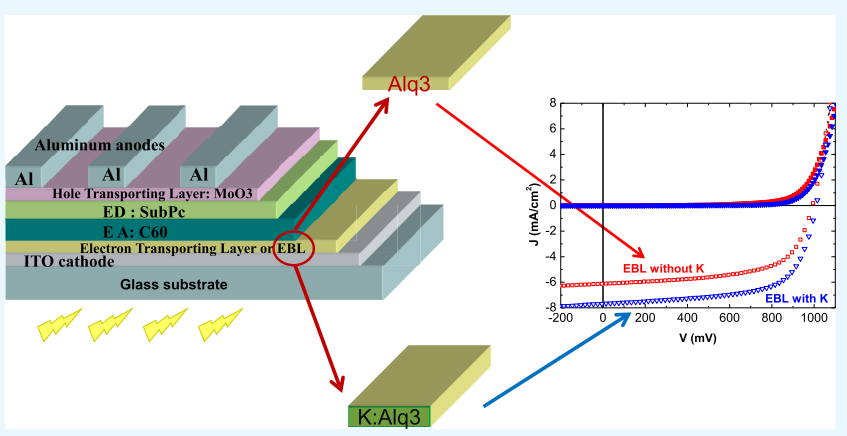
conductivity of the EBL. We demonstrate that K not only behaves as a simple ultrathin layer allowing for the discrimination of the charge carriers at the cathode/organic material interface but also by diffusing into the EBL, it increases its conductivity by 3 orders of magnitude, which allows us to improve the shape of the $J-V$ characteristics and the PHJ-inverted OPV efficiency by more than 33\%. Moreover, we also show that PHJ-inverted OPVs with K in their EBLs are more stable than those with $\mathrm{Alq}_{3}$ alone.

\section{INTRODUCTION}

Organic photovoltaic (OPV) cells with their lightweight, flexibility, and semitransparency appear to be complementary to the Si modules. This makes them promising for a bright future. The classical configuration of OPVs (classical OPVs) consists of an organic layer sandwiched between a high-workfunction $\left(W_{\mathrm{F}}\right)$ transparent conductive electrode, usually indium tin oxide (ITO), as the bottom anode and a small work function electrode as the top cathode. However, the $W_{\mathrm{F}}$ of the top cathode being small, these classical OPVs are not stable due to their sensitivity to humidity and oxygen, and it was shown that inverted OPVs, i.e., OPVs whose bottom electrode was the cathode and the top electrode was the anode, were far more stable. ${ }^{1}$ Inverted OPVs, with a low- $W_{\mathrm{F}}$-modified ITO and a high-work-function modified metal as the top anode allows for improving the OPV lifetime. Therefore, it is of great interest to work on inverted OPVs.

The organic active layer, which is responsible for the absorption of light and charge carrier generation, consists of, at least, two organic materials, an electron donor and an electron acceptor. When these two materials are blended, resulting in a bulk heterojunction $(\mathrm{BHJ})$, quite a high power conversion efficiency (PCE) can be achieved due to a large-area interface between the electron donor and the electron acceptor., ${ }^{2,3}$ Usually, in BHJ-OPVs, the electron donor is a polymer. This allows for obtaining sufficiently fine material domains of the same order of magnitude as that of the exciton diffusion length, which allows for excitons to meet an electron donor/electron acceptor interface and to dissociate into free charges. Nevertheless, the use of small molecules exhibits several advantages such as ease of synthesis, inherent monodispersity, a well-defined structure, and simple purification. All this makes that high power conversion efficiency OPVs with small molecule-based donor materials were carried out. ${ }^{4,5}$ However, whatever the electron donor used, it is not easy to control and stabilize the morphology of the BHJ-OPVs. ${ }^{6}$ Therefore, it could be interesting to use small molecules in planar heterojunctions (PHJs), and such planar structures have already allowed to achieve high power conversion efficiency. Although $\mathrm{BHJ}-\mathrm{OPV}$ are generally more efficient than $\mathrm{PHJ}$ OPVs, the latter have several advantages in fundamental works as simple models to investigate interfaces of the OPVs. ${ }^{8}$

Received: October 28, 2020

Accepted: January 11, 2021

Published: March 2, 2021 
Therefore, in the present work, we have studied PHJ-OPVs, using commercial small molecules as organic materials, and we have focused our study on the effect of a new original buffer layer between the cathode and the electron acceptor, the electron donor being SubPc and the electron acceptor being $\mathrm{C}_{60}$. Indeed, to achieve a good band matching with the organic materials, i.e., to modulate the $W_{\mathrm{F}}$ of the electrodes, it is necessary to introduce buffer layers at the interfaces of electrodes/organic materials. In fact, interface engineering is very important. It not only enables high carrier extraction efficiency from the organic materials but also permits better charge transport. In the case of the anode, it is necessary to have a high $W_{\mathrm{F}}$, and $\mathrm{MoO}_{3}$, with $W_{\mathrm{F}} \geq 5.3 \mathrm{eV}$, is a very efficient hole-transporting layer (HTL). ${ }^{9}$ For instance, even if the $W_{\mathrm{F}}$ of the metal anode is small, such as that of $\mathrm{Al}$ with $W_{\mathrm{F}}$ $=4.3 \mathrm{eV}$, when this metal is coupled with $\mathrm{MoO}_{3}$, the hybrid electrode $\mathrm{Al} / \mathrm{MoO}_{3}$ is very efficient in extracting holes. ${ }^{10}$ Therefore, in the present work, we used $\mathrm{MoO}_{3}$ as the HTL and we focused our interest on the cathode/electron acceptor interface. We show that it is possible to improve very significantly the inverted OPV performance using an original hybrid buffer layer. As a matter of fact, the electrontransporting layer (ETL) depends on the OPV structure; in the case of BHJ-inverted OPV, the ETL is usually a low-workfunction oxide, such as $\mathrm{ZnO}$ or $\mathrm{TiO}_{2}{ }^{11,12}$ In the case of $\mathrm{PHJ}$ OPVs, the ETL, which is called the exciton blocking layer (EBL), is a large-band-gap organic material such as BCP or $\mathrm{Alq}_{3} \cdot{ }^{13-15}$ It is known as an EBL because it is supposed that its large band gap prevents exciton quenching by the metal cathode. $^{13-19}$ Additionally, in PHJ- classical OPVs, it is proposed that the EBL also protects the organic active layer from metal diffusion, ${ }^{16}$ and it can also work as an optical spacer. ${ }^{17}$ Moreover, it is well known that interface dipoles are often present at organic/metal interfaces, ${ }^{18}$ and it was shown that surface dipoles can be formed and can lower the work function of electrodes upon EBL deposition, which allows for the reduction of the ITO work function and permits better carrier collection. ${ }^{19}$ The optimum thickness of this layer may depend on its nature, and it may be thinner ${ }^{20}$ or thicker; ${ }^{21}$ but overall, the studies converge toward an optimum thickness of the order of $8-10 \mathrm{~nm} \cdot{ }^{13-19,21-23}$ This is the reason we chose a thickness of $9 \mathrm{~nm}$ in our study. $\mathrm{Alq}_{3}$ was chosen as the EBL due to the fact that it significantly increases the lifetime of the OPVs. The reason why $\mathrm{Alq}_{3}$ improves the lifetime of OPVs in comparison with $\mathrm{BCP}$ is that after deposition, the amorphous state of $\mathrm{Alq}_{3}$ is stable, while it is not so in the case of $\mathrm{BCP}$, which tends to crystallize fast. ${ }^{14,24}$ The thickness of $9 \mathrm{~nm}$ is too high to permit an efficient tunnel effect. Therefore, it was proposed that metal diffusion into the EBL during the top electrode deposition induces defect states, which allow for electron transport through the EBL. ${ }^{25}$ In the case of inverted OPV, there is no metallic diffusion into the EBL and the optimum EBL thickness, $9 \mathrm{~nm}$, cannot be used. Nevertheless, since earlier studies converge toward an optimum thickness of $9 \mathrm{~nm}$, it would be very interesting to overpass this bottleneck.

In the present work, to use an EBL with a thickness of $9 \mathrm{~nm}$, for the first time to our knowledge, outside perovskite-based photovoltaic cells, ${ }^{26} \mathrm{~K}$ is introduced into the EBL of PHJinverted OPVs. We show that $\mathrm{K}$ is very efficient since it allows for obtaining an improvement of the fill factor, FF, the short circuit current, $J_{s c}$ and the open-circuit voltage, $V_{\text {oc }}$. These result in an outstanding increase of the OPV power conversion efficiency (PCE) of $33 \%$.

\section{EXPERIMENTAL SECTION}

2.1. Organic Photovoltaic Cell Realization and Characterization. The preparation of the ITO-coated glass substrates and the experimental techniques used for the OPV realization have been presented previously. ${ }^{27}$ Two types of OPVs were realized (Figures S1 and S2, Supporting information S.1):

- Without K: ITO $/ \mathrm{Alq}_{3} / \mathrm{C}_{60} / \mathrm{SubPc} / \mathrm{MoO}_{3} / \mathrm{Al}$

- With K: ITO $/ \mathrm{K} / \mathrm{Alq}_{3} / \mathrm{C}_{60} / \mathrm{SubPc} / \mathrm{MoO}_{3} / \mathrm{Al}$

The deposition processes of $\mathrm{Alq}_{3}, \mathrm{C}_{60}, \mathrm{SubPc}, \mathrm{MoO}_{3}$, and $\mathrm{Al}$ have already been described and are recalled in Supporting Information S.2. The deposition rates and optimum thicknesses have already been optimized, ${ }^{26}$ and they were controlled using a quartz monitor. In addition to these layers already used in OPVs, we introduced potassium into the ETL of some OPVs. Potassium was deposited by the Joule effect under vacuum. To obtain pure $\mathrm{K}$ thin films, we used potassium dispensers provided by Saes Getters. Using such dispensers allows for very accurate control of the deposition rate of potassium simply by controlling the current supply. The deposition rate used was $0.03 \mathrm{~nm} / \mathrm{s}$, and the probed thickness of the $\mathrm{K}$ layer was between 0.7 and $4 \mathrm{~nm}$.

All OPVs were studied using an automated $I-V$ tester (see Supporting Information S.3.1), while the external quantum efficiency (EQE) was measured on apparatus built in our laboratory (Supporting Information S.3.2).

2.2. Thin-Film Characterizations. To study the influence of $\mathrm{K}$ on the properties of the stacked layers, we proceeded to different characterizations. Some of them are original and are described below, while some others have already been used in our laboratory and are described in the Supporting Information S.4: scanning electron microscopy (SEM), atomic force microscopy (AFM), X-ray photoelectron spectroscopy (XPS), optical transmission, and absorption measurements.

We proceeded to the electrical characterization of the ETL. The resistivity of the $\mathrm{Alq}_{3}$-ETL being quite large, we used specific longitudinal geometry. In this longitudinal configuration, aluminum electrodes were deposited onto glass substrates that had a width of $10 \mathrm{~mm}$, while the distance between the electrodes was varied from 100 to $1000 \mu \mathrm{m}$ (Figure S3, Supporting Information S1.3). To avoid very high resistances, the thickness of the $\mathrm{Alq}_{3}$ layer was $90 \mathrm{~nm}$ and that of the $\mathrm{K}$ layer was $15 \mathrm{~nm}$, i.e., the $\mathrm{K} / \mathrm{Alq}_{3}$ ratio was equal to that of the optimum ETL. The metal of the electrode was aluminum, as it is often used in classical OPV as the cathode above the $\mathrm{Alq}_{3}$ exciton blocking layer.

\section{EXPERIMENTAL RESULTS}

3.1. Solar Cell Characterization. As mentioned above, it is known that in the case of PHJ-CLASSICAL OPVs, the optimum thickness of the EBL is $9 \mathrm{~nm}$, whatever the material used, $\mathrm{BCP}, \mathrm{Alq}_{3}$, or any other molecule with a similar band structure. $^{13-16}$ Therefore, in the present study, we used this thickness for the EBL. The PHJ-inverted OPVs were fabricated with the architecture of ITO $(100 \mathrm{~nm}) / \mathrm{EBL} / \mathrm{C}_{60}(45 \mathrm{~nm}) /$ $\operatorname{SubPc}(16 \mathrm{~nm}) / \mathrm{MoO}_{3}(7 \mathrm{~nm}) / \mathrm{Al}(100 \mathrm{~nm})$, with the EBL $=$ $\mathrm{Alq}_{3}(9 \mathrm{~nm})$ or $\mathrm{K}(x \mathrm{~nm}) / \mathrm{Alq}_{3}(9 \mathrm{~nm})$ (Figures $\mathrm{S} 1$ and $\mathrm{S} 2$, Supporting Information S.1).

To be sure that the results are reproducible, we have probed at least five series of nine inverted OPVs for each EBL.

Surprisingly, some good results can be obtained utilizing $\mathrm{Alq}_{3} \mathrm{EBL}$ of thickness $9 \mathrm{~nm}$ (Figure 1). Nevertheless, with nine 


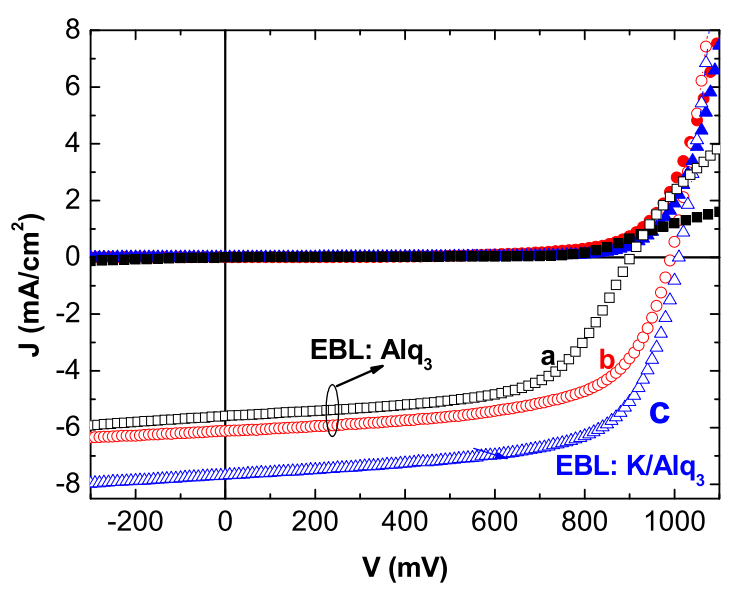

Figure 1. Typical $J-V$ characteristics of inverted OPVs such as ITO/ $\mathrm{EBL} / \mathrm{C}_{60} / \mathrm{SubPc} / \mathrm{MoO}_{3} / \mathrm{Al}$, with $\mathrm{EBL}=\mathrm{Alq}_{3}(9 \mathrm{~nm})(\mathrm{a}, \mathrm{b})$ and $\mathrm{EBL}$ $=\mathrm{K}(1.5 \mathrm{~nm}) / \mathrm{Alq}_{3}(9 \mathrm{~nm})(\mathrm{c})$.

cells being realized for each run of deposition, a large scatter of results was obtained. For instance, the shape of the $J-V$ characteristics of two inverted OPVs deposited during the same run can be significantly different. One exhibits a classical "diode shape" (curve a), while the second exhibits an "Sshaped curve" (curve b), which induces smaller PCE (Figure 1). Such scattered results are due to the large thickness of the insulating EBL. This is discussed below. Therefore, to try to overpass this bottleneck, we have added a thin $\mathrm{K}$ layer at the $\mathrm{ITO} / \mathrm{Alq}_{3}$ interface. In terms of absolute value, the work function of $\mathrm{K}$ is very small, $W_{\mathrm{FK}}=2.5 \mathrm{eV}$, which must improve the band matching between the ITO cathode and the organic layer. The curve obtained after introduction of $\mathrm{K}$ corresponds to the curve $\mathrm{c}$ (Figure 1). We can observe that $\mathrm{K}$ allows for the strong improvement of all of the inverted OPV parameters, mainly the fill factor FF and the short circuit current $J_{s c}$, while the open-circuit voltage, $V_{\text {oc }}$ increases more moderately. The result of all of these improvements is a remarkable increase in PCE of the inverted OPVs.

The best cell performances were $V_{\text {oc }}=1.01 \mathrm{~V}, J_{\mathrm{sc}}=7.68$ $\mathrm{mA} / \mathrm{cm}^{2}, \mathrm{FF}=65 \%$, and $\mathrm{PCE}=5.00 \%$ for the $\mathrm{PHJ}$-inverted OPV with a hybrid EBL such as $\mathrm{K}(1.5 \mathrm{~nm}) / \mathrm{Alq}_{3}(9 \mathrm{~nm})$, while they were $V_{\mathrm{oc}}=0.99 \mathrm{~V}, J_{\mathrm{sc}}=6.12 \mathrm{~mA} / \mathrm{cm}^{2}, \mathrm{FF}=61 \%$, and $\mathrm{PCE}=3.76 \%$ when the $\mathrm{EBL}$ only contained $\mathrm{Alq}_{3}(9 \mathrm{~nm})$. This means that due to the presence of $\mathrm{K}$, the PCE of the PHJinverted OPVs is enhanced by more than $33 \%$. It must be mentioned that in the case of the PHJ-inverted OPV with Sshaped characteristics, the measured parameters were $V_{\mathrm{oc}}=0.9$ $\mathrm{V}, J_{\mathrm{sc}}=5.59 \mathrm{~mA} / \mathrm{cm}^{2}, \mathrm{FF}=60 \%$, and $\mathrm{PCE}=3.06 \%$. It is obvious that inverted OPVs with the $\mathrm{K} / \mathrm{Alq}_{3} \mathrm{ETL}$ show strongly improved photovoltaic properties and better charge extraction efficiency.

We have used the thickness of the $\mathrm{K}$ layer as a parameter. The study shows that $\mathrm{PHJ}$-inverted OPV performances are highly sensitive to the $\mathrm{K}$ layer thickness (Table 1 ). First, the power conversion efficiency increases up to a $\mathrm{K}$ layer thickness of $1.5 \mathrm{~nm}$, mainly due to $J_{\mathrm{sc}}$ and $\mathrm{FF}$, and beyond this thickness, it decreases, mainly due to $V_{\mathrm{oc}}$ and FF deterioration.

It can be concluded from this study that the PHJ-inverted OPV performances depend strongly on the $\mathrm{K}$ layer thickness.

After probing the influence of the $\mathrm{K}$ layer thickness, we checked the influence of the thickness of the $\mathrm{Alq}_{3}$ layer with and without potassium (Table 1). Without $\mathrm{K}$, for the thinner $\mathrm{Alq}_{3}$ layer, $6 \mathrm{~nm}$ instead of $9 \mathrm{~nm}$, the performance of the $\mathrm{PHJ}$ inverted OPVs is lower. Such a result confirms a previous study dedicated to $\mathrm{PHJ}$-inverted OPVs using a different electron donor. ${ }^{26}$ In the presence of $\mathrm{K}$, since optimum performance is obtained for $1.5 \mathrm{~nm}$ of $\mathrm{K}$, while it decreases for the thicker $\mathrm{K}$ layer, we probed the thicker $\mathrm{Alq}_{3}$ layer, but here too there is no improvement in the performances.

To understand the origin for the increase of $J_{s c}$ resulting from the use of the hybrid EBL, we measured the external quantum efficiency of devices with typical EBL: $\mathrm{Alq}_{3}$ alone (9 $\mathrm{nm}) ; \mathrm{K}$ alone $(1.5 \mathrm{~nm})$; and the hybrid EBL, $\mathrm{K}(1.5 \mathrm{~nm}) / \mathrm{Alq}_{3}$ (9 $\mathrm{nm}$ ) (Figure 2).

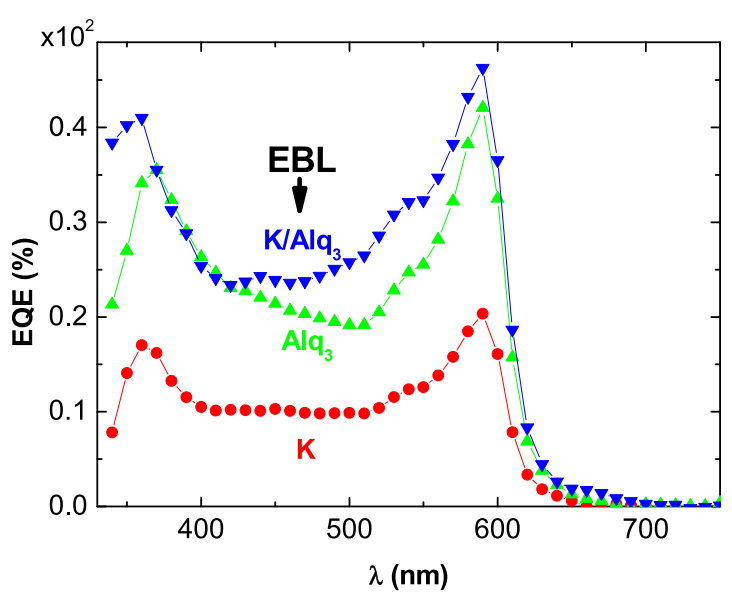

Figure 2. EQE spectra recorded of $\mathrm{PHJ}$-inverted OPVs for different EBLs: (blue solid inverted triangle) $\mathrm{K}(1.5 \mathrm{~nm}) / \mathrm{Alq}_{3}(9 \mathrm{~nm})$, (green solid triangle) Alq3 $(9 \mathrm{~nm})$, and (red solid circle) K (1.5 nm).

If we compare the overall shape of the EQE spectra of $\mathrm{PHJ}$ inverted OPV to that of the absorption spectra, we can

Table 1. Averaged Performance Parameters of PHJ-Inverted OPVs with Different $\mathrm{K}$ and $\mathrm{Alq}_{3}$ Layer Thicknesses

\begin{tabular}{|c|c|c|c|c|c|c|c|}
\hline \multicolumn{2}{|c|}{ ETL } & \multirow[b]{2}{*}{$V_{\mathrm{oc}}(\mathrm{V})$} & \multirow[b]{2}{*}{$J_{\mathrm{sc}}\left(\mathrm{mA} / \mathrm{cm}^{2}\right)$} & \multirow[b]{2}{*}{ FF (\%) } & \multirow[b]{2}{*}{ PCE (\%) } & \multirow[b]{2}{*}{$R_{\mathrm{s}}(\Omega)$} & \multirow[b]{2}{*}{$R_{\text {sh }}(\Omega)$} \\
\hline $\mathrm{K}(\mathrm{nm})$ & $\mathrm{Alq}_{3}(\mathrm{~nm})$ & & & & & & \\
\hline 0 & 6 & $0.94 \pm 0.05$ & $5.5 \pm 0.6$ & $48 \pm 4$ & $2.45 \pm 0.75$ & 40 & 1200 \\
\hline 0 & 9 & $0.94 \pm 0.05$ & $5.6 \pm 0.6$ & $57 \pm 4$ & $3.00 \pm 0.65$ & 20 & 1800 \\
\hline 0.7 & 9 & $0.95 \pm 0.04$ & $5.70 \pm 0.4$ & $60 \pm 2$ & $3.20 \pm 0.50$ & 20 & 1500 \\
\hline 1.5 & 9 & $1.00 \pm 0.02$ & $7.30 \pm 0.4$ & $63 \pm 2$ & $4.60 \pm 0.40$ & 15 & 1600 \\
\hline 1.5 & 12 & $0.93 \pm 0.03$ & $6.70 \pm 0.4$ & $58 \pm 3$ & $3.53 \pm 0.40$ & 30 & 1000 \\
\hline 2.5 & 9 & $0.92 \pm 0.03$ & $6.45 \pm 0.4$ & $55 \pm 2$ & $3.30 \pm 0.40$ & 15 & 1000 \\
\hline 4 & 9 & $0.85 \pm 0.04$ & $6.50 \pm 0.5$ & $50 \pm 3$ & $2.75 \pm 50$ & 15 & 1000 \\
\hline 1.5 & 0 & $0.83 \pm 0.04$ & $5.25 \pm 0.4$ & $43 \pm 3$ & $1.90 \pm 0.50$ & 15 & 1000 \\
\hline
\end{tabular}


attribute the EQE signal to the different contributions of each constituent (Figures 2, 3, and S5.1).

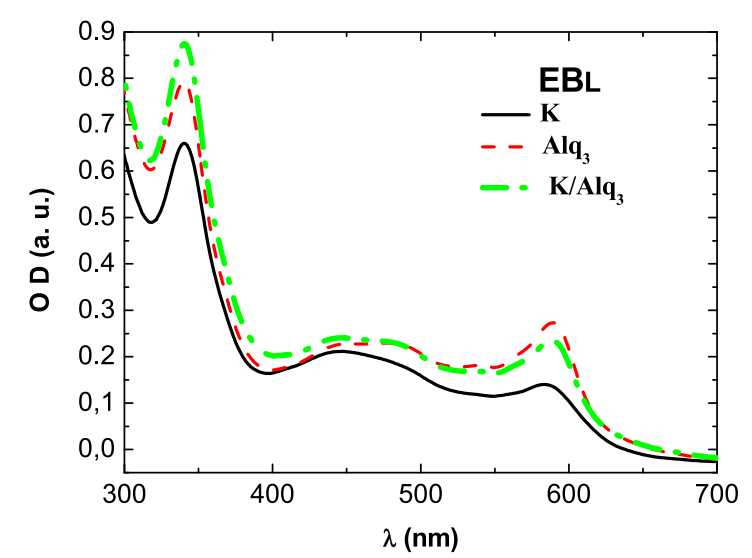

Figure 3. Absorption spectra of ITO/EBL/ $\mathrm{C}_{60} / \mathrm{SubPc}$ with $\mathrm{K}$ (black line), $\mathrm{Alq}_{3}$ (red dashed line), and $\mathrm{K} / \mathrm{Alq}_{3}$ (green dashed-dotted line) as the EBL.

In the EQE spectra, the response situated between 500 and $650 \mathrm{~nm}$ corresponds to a contribution of SubPc. The signal below $400 \mathrm{~nm}$ corresponds to the second absorption band of SubPc and that of $\mathrm{C}_{60}$, while the intermediate domain between these two contributions must mainly be attributed to $\mathrm{C}_{60}$. Therefore, both organic layers participate in exciton creation, the main contributions being by SubPc.

From the three different absorption spectra, it can be seen that when $\mathrm{K}$ alone is the EBL, the absorption coefficient is smaller than those obtained with other EBLs, while it is not so different for the other two EBLs. Regarding the EQE spectra, the smaller signal obtained when $\mathrm{K}$ is the EBL is in good agreement with the corresponding $J_{\mathrm{sc}}$ values deduced from the $J-V$ characteristics. In the case of the other EBLs, the signal due to SubPc obtained with $\mathrm{K} / \mathrm{Alq}_{3}$ as the EBL is clearly higher than that obtained with $\mathrm{Alq}_{3}$ alone. Even if it is less spectacular, the signal is also higher in the intermediate domain, which corresponds to the $\mathrm{C}_{60}$ contribution. The whole spectra show that the ratio of the $J_{\text {sc }}$ obtained with the hybrid EBL to the $J_{\text {sc }}$ obtained with $\mathrm{Alq}_{3}$ alone is 1.2, which is in good agreement with the value deduced from the $J-V$ characteristics.

Finally, we proceeded to an aging-effect study. Following the protocol proposed in ref 28, the procedure used to study the aging process of the $\mathrm{PHJ}$-inverted OPVs corresponds to the intermediate level labeled "level 2". The operational lifetimes have been measured under AM1.5, in air and at room temperature, $25^{\circ} \mathrm{C}$. The process used was as follows: between every measure, samples were stored in air and in daylight, the cells being in open-circuit conditions. This process is called "intermittent illumination". Typical degradation curves show that, as usual, the power conversion efficiency first drops fast and then more slowly (Figure 4). It appears that $\mathrm{K}$ incorporation into the EBL does not decrease the lifetime of the PHJ-inverted OPV; on the contrary, it appears to increase its stability.

If we take into account the operational lifetime $t \eta_{0 / 2}$, which is defined as the time at which the initial performances have been divided by 2 , in the case of the hybrid EBL, $t \eta_{0 / 2}$ is around $40 \mathrm{~h}$, while it is around $20 \mathrm{~h}$ for $\mathrm{Alq}_{3} \mathrm{EBL}^{29}$ For the first time, this preliminary study shows that the presence of $K$,

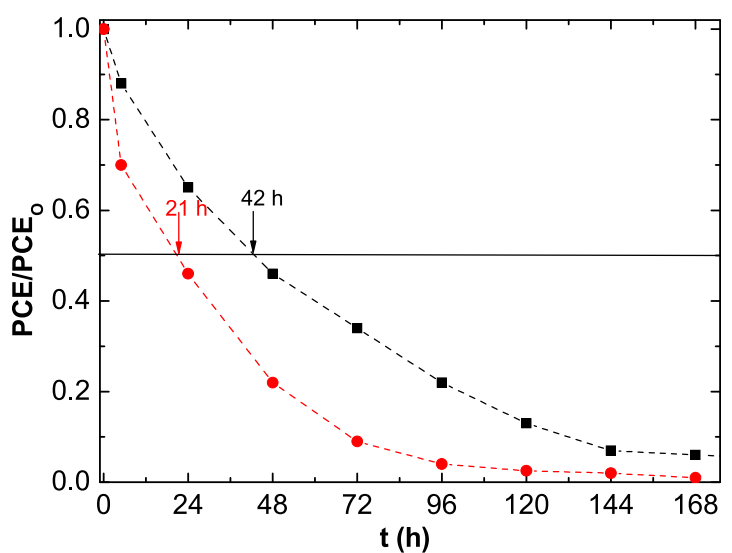

Figure 4. Variation with time of the normalized efficiency of PHJinverted OPVs with $\mathrm{K} / \mathrm{Alq}_{3}$ (black solid square) and $\mathrm{Alq}_{3}$ (red solid circle) as EBLs.

despite its low work function value, does not penalize the lifetime of the PHJ-inverted OPVs. In the case of organic lightemitting diodes, it was shown that when the electron-injecting material is changed from $\mathrm{LiF}$ to $\mathrm{LiCoO}_{2}$, there is a significant improvement of the lifetime. ${ }^{30}$ This lifetime increase is attributed to the fact that during deposition there is $\mathrm{LiCoO}_{2}$ decomposition and formation of $\mathrm{LiO}$, which has been reported to reduce the destructive interaction between the cathode and $\mathrm{Alq}_{3}{ }^{31}$ In the case of OPVs, similar lifetime improvement was obtained by substituting $\mathrm{CsCO}_{3}$ with $\mathrm{LiF}$, which delayed oxygen contamination of the organic materials. ${ }^{32}$ It is concluded that oxides, such as $\mathrm{LiO}, \mathrm{CsCO}_{3}$, etc., allow for the improvement of the lifetime of the devices. In the present work, the presence of $\mathrm{K}$, which, as we see in the next paragraph, is oxidized, may play the same positive role in the OPV lifetime.

3.2. Thin-Film Characterizations. To understand the effect of $\mathrm{K}$ on the OPV properties, we conducted complementary characterizations. The resistivity of the EBL was estimated using transversal structures. The thicknesses of the different layers were $100 \mathrm{~nm}$ for ITO, $1.5 \mathrm{~nm}$ for $\mathrm{K}$, and 9 $\mathrm{nm}$ for $\mathrm{Alq}_{3}$, while that of $\mathrm{C}_{60}$ was $90 \mathrm{~nm}$ and that of $\mathrm{Al}$ was $100 \mathrm{~nm}$. The thickness of the $\mathrm{C}_{60}$ layer was double that used in the inverted OPVs to avoid leakage currents. Such a device configuration is known as an electron-only device. ${ }^{25}$ ITO being the anode and $\mathrm{Al}$ the cathode, the $J-V$ characteristics depend strongly on the presence or absence of $\mathrm{K}$ (Figure 5). A ratio of 3 orders of magnitude was measured for the current.

The resistivity ratio deduced from the resistance measured on transversal structures is of 3 orders of magnitude, with resistivity values of $5.5 \times 10^{4} \Omega / \mathrm{cm}$ in the case of $\mathrm{K} / \mathrm{Alq}_{3}$ and $6.5 \times 10^{7} \Omega / \mathrm{cm}$ in the case of $\mathrm{Alq}_{3}$. This resistivity ratio was in agreement with the results obtained using longitudinal structures, even if in this case the gap between electrodes ranges from 100 to $1000 \mu \mathrm{m}$, which is very far from the actual device thickness that induces high uncertainty (see Figure S3, Supporting Information S1.3).

Typical $J-V$ characteristics of electron-only devices with a thickness of $100 \mathrm{~nm}$ exhibit a classical behavior for this kind of device. After showing an ohmic dependence at low voltage, they then exhibit a nearly quadratic dependence of current with voltage. Such dependence indicates a space charge limited current (SCLC) mechanism. Therefore, the carrier mobility can be estimated using the Mott-Gurney law ${ }^{33}$ 


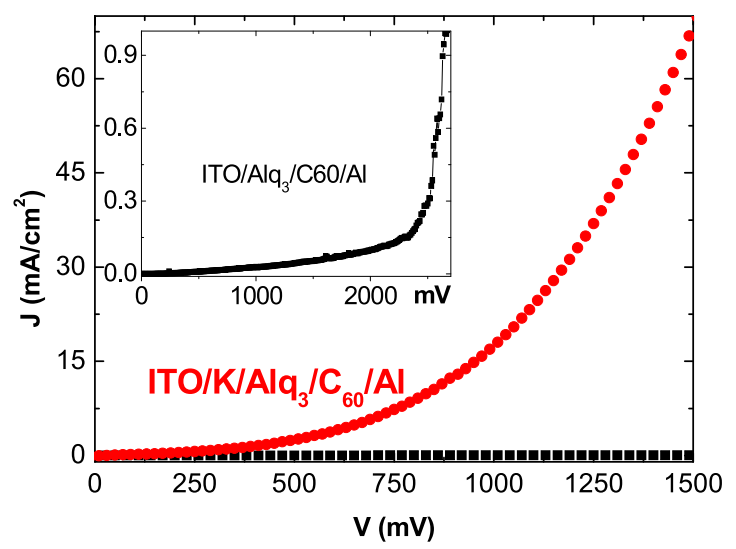

Figure 5. $J-V$ characteristics of $\mathrm{ITO} / \mathrm{Alq}_{3} / \mathrm{C}_{60} / \mathrm{Al}$ (black solid square) and $\mathrm{ITO} / \mathrm{K} / \mathrm{Alq}_{3} / \mathrm{C}_{60} / \mathrm{Al}$ (red solid circle) structures.

$$
J=9 / 8 \varepsilon_{\mathrm{r}} \varepsilon_{0} \mu_{\mathrm{e}} V^{2} / L^{3}
$$

where $\varepsilon_{\mathrm{r}}$ is the relative permittivity, $\varepsilon_{0}$ is the permittivity in vacuum, $\mu_{\mathrm{e}}$ is the electron mobility, $V$ is the applied voltage, $L$ is the active layer thickness, and $J$ is the current density. The electron mobility deduced for $\mathrm{Alq}_{3}$ is $\mu_{\mathrm{e}}=1.1 \times 10^{-7} \mathrm{~cm} /(\mathrm{V}$ $\mathrm{s})$. This value is close to the mobility of $\mathrm{Alq}_{3}$ that is already published. ${ }^{34}$ In the presence of $\mathrm{K}$, the mobility is significantly higher with $\mu_{\mathrm{e}}=7 \times 10^{-5} \mathrm{~cm} /(\mathrm{V} \mathrm{s})$.

Therefore, it observed that $\mathrm{K}$ doping into $\mathrm{Alq}_{3}$ increases the electron mobility and conductivity.

Such a high resistivity decrease should be due to $\mathrm{K}$ diffusion into the $\mathrm{Alq}_{3}$ layer. For the first time, we have checked the presence of $\mathrm{K}$ in the samples $\mathrm{ITO} / \mathrm{K} / \mathrm{Alq}_{3}$ using energydispersive spectrometry (EDS). This attests to the presence of K (Figure S5.2, Supporting Information), but the layers being very thin, it is impossible to quantify the results. Moreover, with the depth resolution of this technique being much less than the whole thickness of the $\mathrm{K} / \mathrm{Alq}_{3}$ bilayer, it is impossible to conclude when a possible diffusion of $\mathrm{K}$ occurs.

To check if $\mathrm{K}$ diffuses into $\mathrm{Alq}_{3}$, we have used glass/ITO $(100 \mathrm{~nm}) / \mathrm{Alq}_{3}(9 \mathrm{~nm})$ and glass/ITO $(100 \mathrm{~nm}) / \mathrm{K}(1.5 \mathrm{~nm}) /$ $\mathrm{Alq}_{3}(9 \mathrm{~nm})$ structures for an XPS study.

From the survey spectra, it can be concluded that the rate of overlap of the ITO by the EBL layer is not completely homogeneous, as evidenced by the presence of In and Sn peaks (Figure 6). Nevertheless, no contaminant is detected since C

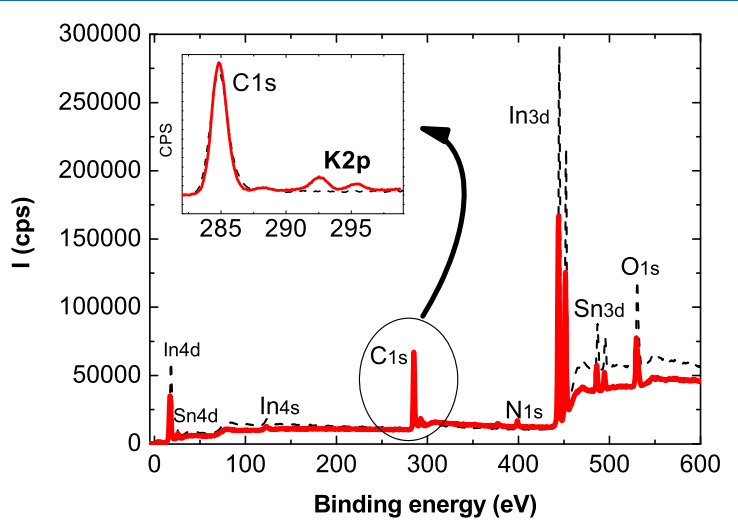

Figure 6. Survey spectra of ITO/ $\mathrm{Alq}_{3}$ (black dashed line) and ITO/ $\mathrm{K} / \mathrm{Alq}_{3}$ (red line). The inset shows the $\mathrm{C} 1$ s window with $\mathrm{K} 2 \mathrm{p}$ clearly visible in the case of $\mathrm{ITO} / \mathrm{K} / \mathrm{Alq}_{3}$.
$1 \mathrm{~s}, \mathrm{O} 1 \mathrm{~s}$, and $\mathrm{N} 1 \mathrm{~s}$ peaks are obtained from $\mathrm{Alq}_{3}$. More interestingly, it can be seen in the inset of the figure that while $\mathrm{K}$ is absent in the spectrum of the ITO/Alq $\mathrm{A}_{3}$ bilayer, it is clearly visible in that of $\mathrm{ITO} / \mathrm{K} / \mathrm{Alq}_{3}$. This implies that $\mathrm{K}$ diffused into the $\mathrm{Alq}_{3}$ layer. It can be concluded from this XPS approach that there is spontaneous incorporation of $\mathrm{K}$ into $\mathrm{Alq}_{3}$; moreover, the binding energy of the $\mathrm{K} 2 \mathrm{p}$ doublet ( $\mathrm{K}$ $2 \mathrm{p}_{1 / 2}=295.6 \mathrm{eV} ; \mathrm{K} 2 \mathrm{p}_{3 / 2}=292.8 \mathrm{eV}$ ) shows that it is oxidized.

With the hybrid EBL being quite thin, to check more carefully the diffusion of $\mathrm{K}$ into $\mathrm{Alq}_{3}$, we probed samples with the same $\mathrm{K} / \mathrm{Alq}_{3}$ thickness ratio but using thicker layers, i.e., $\mathrm{K}$ $(5 \mathrm{~nm}) / \mathrm{Alq}_{3}(40 \mathrm{~nm})$, instead of $\mathrm{K}(1.5 \mathrm{~nm}) / \mathrm{Alq}_{3}(9 \mathrm{~nm})$. It can be seen in Figure S5.8 that the signal due to $\mathrm{K}$ is still clearly visible at the surface of the bilayer $\mathrm{K} / \mathrm{Alq}_{3}$. This result confirms $\mathrm{K}$ diffusion into $\mathrm{Alq}_{3}$. On the other hand, from Figure S5.9, it can be deduced that the valence band value of $\mathrm{Alq}_{3}$ is situated at around $1.82 \mathrm{eV}$ below the Fermi level. When $\mathrm{K}$ is introduced, the valence band value of $\mathrm{K} / \mathrm{Alq}_{3}$ shifts toward $2.70 \mathrm{eV}$.

Besides, we have investigated a series of SEM images to check the effect of $\mathrm{K}$ incorporation on inverted OPVs. First, we found that after $\mathrm{K}$ incorporation, the density of clusters visible at the surface of the $\mathrm{Alq}_{3}$ layer increases (Figures 7 and S5.3).

To check the morphology difference induced by the presence of $\mathrm{K}$ in the EBL, we conducted an AFM study. The AFM images of ITO $/ \mathrm{Alq}_{3}$ and ITO/K $(1.5 \mathrm{~nm}) / \mathrm{Alq}_{3}(9 \mathrm{~nm})$ cathodes confirm the difference in cluster density evidenced by the SEM study (Figure 8). The root-mean-square (RMS) roughness of $\mathrm{ITO} / \mathrm{Alq}_{3}(9 \mathrm{~nm})$ and $\mathrm{ITO} / \mathrm{K}(1.5 \mathrm{~nm}) / \mathrm{Alq}_{3}(9$ $\mathrm{nm}$ ) coated ITO was 2 and $2.5 \mathrm{~nm}$, respectively. An AFM image corresponding to an EBL such as $\mathrm{K}(2.5 \mathrm{~nm}) / \mathrm{Alq}_{3}$ (9 $\mathrm{nm}$ ) is presented in Figure S5.4. Its RMS roughness is $7.5 \mathrm{~nm}$, which shows that it increases with the thickness of the K layer.

It was shown that the presence or absence of $\mathrm{K}$ in the EBL disturbs the absorption spectra of the PHJ-inverted OPV. Nevertheless, all cathodes possess similar transmission, very close to that of the ITO (Figure S5.5, Supporting Information). The absorption threshold of the EBL with or without $\mathrm{K}$ is the same, which means that there is no large band-gap modification.

Therefore, we next conducted a careful SEM study of the $\mathrm{PHJ}$-inverted OPVs with and without $\mathrm{K}$ to check if the morphology of the devices could explain these perturbations. We present the images of the cross sections of more typical examples, i.e., cells in which the EBL consist of a $\mathrm{K}$ layer alone $(1.5 \mathrm{~nm})$, a $\mathrm{Alq}_{3}$ layer alone $(9 \mathrm{~nm})$, and a hybrid EBL K (1.5 $\mathrm{nm}) / \mathrm{Alq}_{3}(9 \mathrm{~nm})$ (Figure 9). While the cross section of the $\mathrm{PHJ}$-inverted $\mathrm{OPV}$ with $\mathrm{Alq}_{3}$ as the EBL is homogeneous, that with $\mathrm{K}$ is not. When $\mathrm{K}$ is the ETL, a succession of bumps and hollow areas is clearly visible. The dependence of the morphology on the EBL is visible all along the cross section (Figure S5.6, Supporting information). These inhomogeneities, mediated by K, can induce light leakage paths, which can justify the lesser absorption of these devices. In the case of $\mathrm{K} /$ $\mathrm{Alq}_{3} \mathrm{EBL}$, no such paths are visible. The cross section is homogeneous, and only some small heaps are present at the surface of the device. The thickness of the whole structure $(\mathrm{K}) / \mathrm{Alq}_{3} / \mathrm{C}_{60} / \mathrm{SubPc}$ is around $70 \mathrm{~nm}$, which corresponds to the expected value. In the case of the structure $\mathrm{K} / \mathrm{C}_{60} / \mathrm{SubPc}$, the thickness varies between 60 and $90 \mathrm{~nm}$ due to the inhomogeneities. Regarding the composition of the heaps present at the surface of the structures, it can be noted that as expected, they have the same composition as the rest of the 

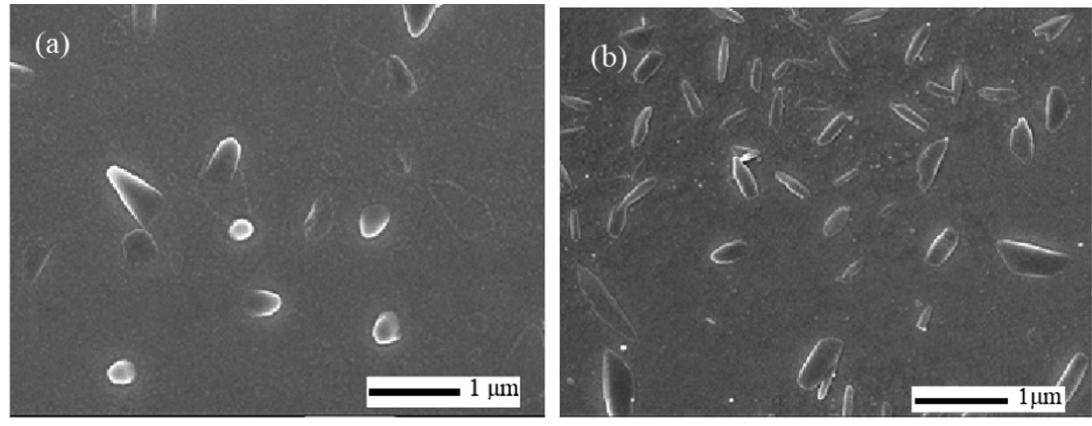

Figure 7. Surface image of (a) ITO/Alq ${ }_{3}$ and (b) ITO/K/Alq $\mathrm{I}_{3}$ cathodes.
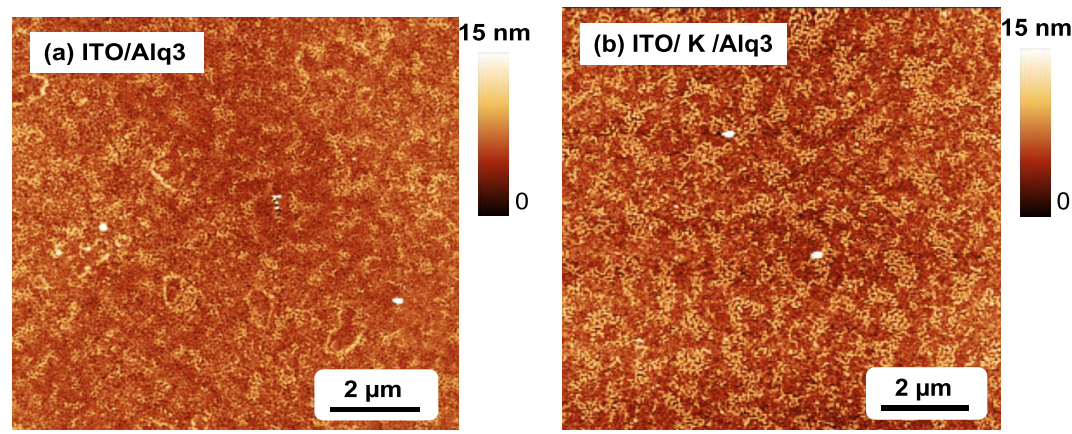

Figure 8. AFM images of (a) ITO/ $\mathrm{Alq}_{3}$ and (b) ITO/K/Alq ${ }_{3}$ cathodes.
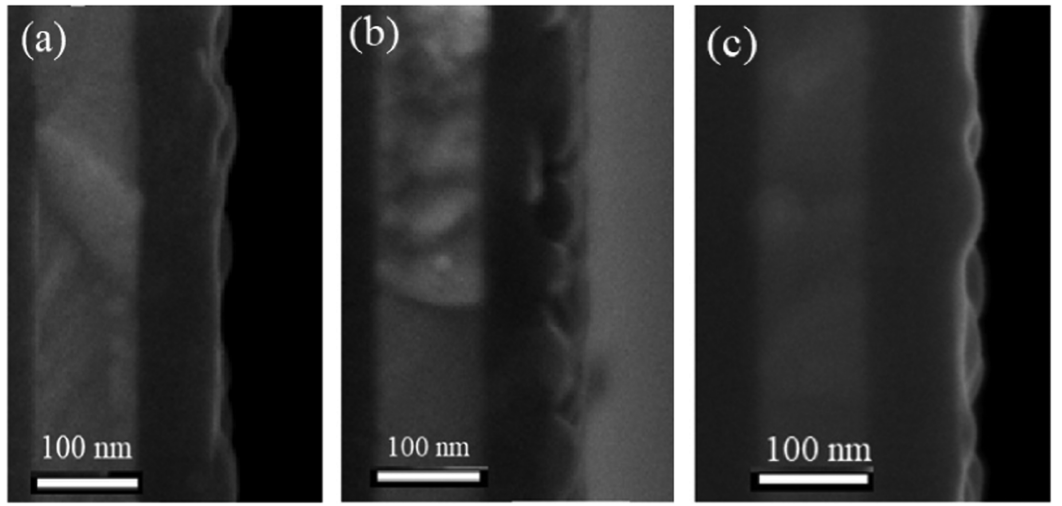

Figure 9. Images of the cross sections of $\mathrm{ITO} / \mathrm{EBL} / \mathrm{C}_{60} / \mathrm{SubPc}$ structures with $\mathrm{EBL}:(\mathrm{a})=\mathrm{Alq}_{3},(\mathrm{~b})=\mathrm{K}$, and $(\mathrm{c})=\mathrm{K} / \mathrm{Alq}_{3}$.

layer, as testified by the images in secondary electrons and the backscattering mode (Figure S5.7, Supporting information).

\section{DISCUSSION}

Before discussing the new results obtained in the present work, we must summarize earlier studies dedicated to the interaction between different alkalines and $\mathrm{Alq}_{3}$. Actually, some alkali compounds, such as $\mathrm{LiF}$ and different Cs compounds, have already been used to improve the organic material/cathode interface. A short presentation of these studies may help us in understanding the positive effect of $\mathrm{K}$ on OPV performances. First of all, it must be noted that some fundamental studies dedicated to the interaction of $\mathrm{Alq}_{3}$ with $\mathrm{K}$ have been published. ${ }^{35,36}$ For instance, it was shown that the interaction between $\mathrm{Alq}_{3}$ and $\mathrm{K}$ does not induce any isomerization of $\mathrm{Alq}_{3}$, while the energy transport gap of $\mathrm{Alq}_{3}$ of $3.05 \mathrm{eV}$ was seen after $\mathrm{K}$ intercalation, which is slightly higher than the optical band gap $E_{\mathrm{g}}=2.9 \mathrm{eV}$. This shows that $\mathrm{K}$ does not induce any band- gap decrease, which retains its potential as an exciton blocking layer.

Regarding $\mathrm{LiF}$, it is well known that it is very efficient as an electron-injection (collection) layer, which was interpreted in terms of dissociation of $\mathrm{LiF}$ and subsequent $\mathrm{Li}$ doping in the organic material or large interface dipole, which induces the lowest unoccupied molecular orbital (LUMO) of the electron acceptor to move close to the Fermi level of the cathode or a tunneling increase by insulating the interface layer. ${ }^{37}$ More precisely, in the case of deposition of an alkaline metal or compound onto a $\mathrm{Alq}_{3}$ layer, due to the low work function of the alkaline, there is no $\mathrm{Alq}_{3}$ structure modification but formation of $\mathrm{Alq}_{3}{ }^{-}$and $\mathrm{Li}^{+}$radicals. ${ }^{38}$ This effect was experimentally studied in the case of $\mathrm{LiF} / \mathrm{Alq}_{3}$, which results in an enhanced electron exchange between the cathode and the electron acceptor. This enhancement may be attributed to a decrease of the barrier between the cathode Fermi level and the highest occupied molecular orbital (HOMO) of the electron donor, decreasing the cathode work function and/or 
creating a voltage drop across the interface layer through dipole formation.

Similar results were obtained when a Cs material was substituted with LiF. There is at least partial decomposition of Cs compounds during their deposition by thermal evaporation. Therefore, when deposited between the cathode and the $\mathrm{Alq}_{3}$ layer, $\mathrm{Cs}^{+}$behaves as $\mathrm{Li}^{+}$, which improves significantly the optoelectronic device performance. In the case of organic lightemitting diodes, the deposition of $\mathrm{CsN}_{3}$ between the cathode and the $\mathrm{Alq}_{3}$ layer induces significant enhancement of lightemitting diode performance. This is attributed to n-type doping with $\mathrm{Cs}$ deposition onto $\mathrm{Alq}_{3}$ and the corresponding decrease of the barrier height at the cathode $/ \mathrm{Alq}_{3}$ interface. ${ }^{39}$ A similar effect has been evidenced when $\mathrm{CsOH}$ is introduced between the cathode and the $\mathrm{Alq}_{3}$ layer. ${ }^{40}$ An electrical study of electron-only devices, $\mathrm{Al} / \mathrm{Cs}_{2} \mathrm{CO}_{3} / \mathrm{Alq}_{3} / \mathrm{Cs}_{2} \mathrm{CO}_{3} / \mathrm{Al}$, shows that the electron mobility is 2 orders of magnitude higher when $\mathrm{Cs}_{2} \mathrm{CO}_{3}$ is present at the $\mathrm{Al} / \mathrm{Alq}_{3}$ interfaces. ${ }^{34}$ This is attributed to charge transfer between $\mathrm{Cs}_{2} \mathrm{CO}_{3}$ and $\mathrm{Alq}_{3}$, which induces $\mathrm{Alq}_{3}$ doping and $\mathrm{Alq}_{3}$ Fermi level shift toward the $\mathrm{Alq}_{3} \mathrm{LUMO}$ level.

We can then use these results to discuss the present results. First, S-shaped $J-V$ curves obtained with $\mathrm{Alq}_{3}$ as the EBL have already been obtained. Sometimes they are present only under light conditions, in which case they are attributed to the disequilibrium of charge carrier densities present in the active layer due to a very large mobility difference between electrons and holes. ${ }^{41,42}$ In other cases, the S-shape is present under light and dark conditions. Such behavior is attributed to the presence of, at least, one rectifying contact. ${ }^{42,43}$ This hypothesis is in agreement with electric simulation, which shows that it is necessary to introduce an opposite diode in the electrical equivalent circuit to obtain a good fit between the experimental and theoretical $J-V$ characteristics. ${ }^{44}$ Here, the $J-V$ characteristics exhibit S-shaped curves, regardless of the light environment, Figure 1 (curves $\square$ ). The purpose of this work is not to further study this effect but simply to explain its presence. As mentioned above, the EBL thickness, $9 \mathrm{~nm}$, is too high to permit an efficient electron tunnel effect. Therefore, electrons must accumulate at the $\mathrm{C}_{60} / \mathrm{Alq}_{3}$ interface, which creates an electric field that opposes the passage of electrons. This results in S-shaped curves. The good results obtained (Figure 1, curve c) can be attributed to variations in the EBL thickness. Actually, the XPS study has shown that In and Sn of ITO are clearly visible in the survey spectra of the EBLs, which means that there are some areas where the ABL thickness is thin enough to permit the detection of In and Sn by surface analysis and therefore to also permit an efficient passage of electrons by the tunnel effect. This justifies that if it is possible to obtain satisfactory results with this type of cell, there is a great dispersion of the results. Therefore, it is necessary to improve the properties of the EBL to suppress the parasite diode effect. This diode effect is due to the poor band matching at the organic material/cathode interface and to the high resistivity of the EBL. Therefore, it is necessary to improve the band matching and the EBL conductivity. These goals are achieved using a hybrid $\mathrm{EBL}, \mathrm{K} / \mathrm{Alq}_{3}$. As shown by the XPS study, the valence band shift due to $\mathrm{K}, 0.9 \mathrm{eV}$, is of the same order of magnitude as that measured when $\mathrm{CsN}_{3}$ is deposited onto $\mathrm{Alq}_{3}{ }^{39}$ This shift was shown to be efficient in decreasing the injection barrier height at the cathode $/ \mathrm{Alq}_{3}$ interface. A similar effect is described when other Cs compounds are introduced between ITO and $\mathrm{Alq}_{3}{ }^{40}$ More- over, as shown by the SCLC study, the presence of $\mathrm{K}$ significantly increases the electron mobility. Therefore, by an analogy among these studies, and following the preceding study discussed above, ${ }^{39,40}$ it can be concluded that the presence of $\mathrm{K}$ induces a decrease of the barrier height at the $\mathrm{ITO} / \mathrm{Alq}_{3}$ interface.

The increase of $\mathrm{FF}$ means that the $\mathrm{K} / \mathrm{Alq}_{3} \mathrm{EBL}$ collects charge more efficiently and decreases charge recombination. Regarding the $J-V$ characteristics of the electron-only devices ITO $/ \mathrm{EBL} / \mathrm{C}_{60} / \mathrm{Al}\left(\mathrm{EBL}=\mathrm{Alq}_{3}\right.$ or $\left.\mathrm{K} / \mathrm{Alq}_{3}\right)$, with ITO being used as the cathode in experiments, the current observed is due to electron injection from ITO. Therefore, the 3 orders of magnitude measured are due to the far better injection properties of the $\mathrm{K} / \mathrm{Alq}_{3} \mathrm{EBL}$. $\mathrm{K}$ incorporation not only increases the EBL conductivity but also reduces the interfacial recombination. The EQE spectrum of the PHJ-OPV with $\mathrm{K}$ is improved in nearly the whole wavelength range up to $600 \mathrm{~nm}$, which is consistent with the $J_{\text {sc }}$ improvement.

Nevertheless, K increases not only the efficiency of the EBL but also its surface roughness, which can create shunt paths. Actually, the active-film thickness being small, any defects in its growth due to the presence of surface protuberances of the substrate induces performance limitation through an increase of the leakage current. This effect is corroborated by the measured values of the dark current: at $V=-0.1 \mathrm{~V}, J_{\mathrm{s}}$ is $2 \times$ $10^{-4}, 3 \times 10^{-4}$, and $30 \times 10^{-4} \mathrm{~mA} / \mathrm{cm}^{2}$ when the thickness of the $\mathrm{K}$ layer is $0,1.5$, and $2.5 \mathrm{~nm}$, respectively. Such an effect results in a decrease of FF and $V_{\mathrm{oc}}$, when K overpasses a critical value, here $1.5 \mathrm{~nm}$.

\section{CONCLUSIONS}

Interfacial layers, inserted between the organic active layer and the electrodes, play a critical role in determining the power conversion efficiency of OPVs. Actually, we used different ETLs in inverted OPVs with the structure of ITO/ETL/ $\mathrm{C}_{60} /$ $\mathrm{SubPc} / \mathrm{MoO}_{3} / \mathrm{Al}$. In this study, a $\mathrm{K}$ layer inserted at the ITO/ $\mathrm{Alq}_{3}$ interface forms a hybrid $\mathrm{K} / \mathrm{Alq}_{3} \mathrm{EBL}$, which modifies cathode properties by overpassing the disadvantages of the insulating property of $\mathrm{Alq}_{3}$, meanwhile retaining its exciton blocking properties.

It is shown that the decisive role of $\mathrm{K}$ doping can be attributed to a reduction of the electron collection barrier and an increase of the conductivity of the EBL layer. We found that $\mathrm{K}$ incorporation into the $\mathrm{EBL}$ layer realized an obvious increase in the power conversion efficiency of $\mathrm{PHJ}$ INVERTED OPVs. The main reason for this improvement is the effective doping of the EBL by $\mathrm{K}$, which increases the EBL conductivity and decreases the barrier height at the ITO/ $\mathrm{C}_{60}$ interface. The best performance is achieved when the $\mathrm{K}$ layer thickness is $1.5 \mathrm{~nm}$.

The PHJ-INVERTED OPV with the best power conversion efficiency of $4.56 \%$ was achieved with the $\mathrm{K} / \mathrm{Alq}_{3}$ hybrid EBL, which corresponds to an improvement of the INVERTED OPV efficiency of more than $33 \%$.

\section{ASSOCIATED CONTENT}

\section{SI Supporting Information}

The Supporting Information is available free of charge at https://pubs.acs.org/doi/10.1021/acsomega.0c05259.

Organic photovoltaic scheme; organic molecules; organic photovoltaic cell deposition process; electrical characterization of the organic photovoltaic cells; 
organic stacked-layer characterizations; and some complementary experimental results (PDF)

\section{AUTHOR INFORMATION}

\section{Corresponding Author}

Linda Cattin - Institut des Matériaux Jean Rouxel, IMN, Université de Nantes, CNRS, Nantes F-44000, France; ๑ orcid.org/0000-0002-8222-5929; Email: Linda.CattinGuenadez@univ-nantes.fr

\section{Authors}

Guy Louarn - Institut des Matériaux Jean Rouxel, IMN, Université de Nantes, CNRS, Nantes F-44000, France

Ludovic Arzel - Institut des Matériaux Jean Rouxel, IMN, Université de Nantes, CNRS, Nantes F-44000, France

Nicolas Stephant - Institut des Matériaux Jean Rouxel, IMN, Université de Nantes, CNRS, Nantes F-44000, France

Mustapha Morsli - Faculté des Sciences et des Techniques, Université de Nantes, Nantes F-44000, France

Jean Christian Bernède - MOLTECH-Anjou, CNRS-UMR 6200, Université de Nantes, Nantes F-44322, France; ๑ orcid.org/0000-0002-1457-1117

Complete contact information is available at: https://pubs.acs.org/10.1021/acsomega.0c05259

\section{Author Contributions}

These authors contributed equally. All authors have given approval to the final version of the manuscript.

\section{Notes}

The authors declare no competing financial interest.

\section{ACKNOWLEDGMENTS}

The authors acknowledge funding from the European Community ERANETMED_ENERG-11-196.

\section{REFERENCES}

(1) Zhang, F.; Xu, X.; Tang, W.; Zhang, J.; Zhuo, Z.; Wang, J.; Wang, J.; Xu, Z.; Wang, Y. Recent developpement of the inverted configuration organic solar cells. Sol. Energy Mater. Sol. Cells 2011, 95, $1785-1799$.

(2) Cui, Y.; Yao, H.; Hong, L.; Zhang, T.; Xu, Y.; Xian, K.; Goa, B.; Qin, J.; Zhang, J.; Wei, Z.; Hou, J. Achieving over $15 \%$ efficiency in organic photovoltaic cells via copolymer design. Adv. Mater. 2019, No. 1808356

(3) Liu, Q.; Jiang, Y.; Jin, K.; Qin, J.; Xu, J.; li, W.; Xiong, J.; Liu, J.; xiao, Z.; Sun, K.; Yang, S.; Zhang, X.; Ding, L. 18\% Efficiency organic solar cells. Sci. Bull. 2020, 272-275.

(4) Leliège, A.; Grolleau, J.; Allain, M.; Blanchard, P.; Demeter, D.; Rousseau, T.; Roncali, J. Small D-p-A systems with s-phenylenebridged accepting units as active materials for organic photovoltaics. Chem. - Eur. J. 2013, 19, 9948-9960.

(5) Ilmin, R.; Haque, A.; Khan, M. S. High efficiency small moleculebased donor materials for organic solar cells. Org. Electron. 2018, 58, $53-62$.

(6) Schaffer, C. J.; Palumbiny, C. M.; Niedermeier, M. A.; jendrzejewski, C.; Santoro, G.; Roth, S. V.; Mller-Buschbaum, P. A direct evidence of morphological degradation on a nanometer scale in polymer solar cells. Adv. Mater. 2013, 25, 6760-6764.

(7) Cnops, K.; Rand, B. P.; Cheyns, D.; Verreet, B.; Empl, M. A.; Heremans, P. 8.4\% efficient fullerene-free organic solar cells exploiting long-range exciton energy transfer. Nat. Commun. 2014, 5, No. 3406. (8) Nakano, K.; Tajima, K. Organic planar heterojunctions: From models for interfaces in bulk heterojunctions to high-performance solar cells. Adv. Mater. 2017, 29, No. 1603269.
(9) Meyer, J.; Hamwi, S.; Kröger, M.; Kowalsky, W.; Riedl, T.; Kahn, A. Transitionn metal oxides for organic electronics: Energetics, device physics and applications. Adv. Mater. 2012, 24, 5408-5427.

(10) Sun, F.-Z.; Shi, A.-L.; Xu, Z.-Q.; Wei, H.-X.; Li, Y.-Q.; Lee, S.T.; Tang, J.-X. Efficient inverted polymer solar cells with thermalevaporated and solution-processed small molecular electron extraction layer. Appl. Phys. Lett. 2013, 102, No. 133303.

(11) Das, S.; Alford, T. L. Optimization of the zinc oxide electron transport layer in $\mathrm{P}_{3} \mathrm{HT}: \mathrm{PC}_{61} \mathrm{BM}$ based organic solar cells by annealing and yttrium doping. RSC Adv. 2015, 5, 45586-45591.

(12) Wiranwetchayan, O.; Zhang, Q.; Zhou, X.; Liang, Z.; Singjai, P.; Cao, G. Impact of the morphology of $\mathrm{TiO}_{2}$ films as cathode buffer layer on the efficiency of inverted-structure polymer solar cells. Chalcogenide Lett. 2012, 9, 157-163.

(13) Rand, B. P.; Lian, J.; Xue, J.; Holmes, R. J.; Thompson, M. E.; Forrest, S. R. Organic Double-Heterostructure Photovoltaic Cells Employing Thick Tris(acetylacetonato) ruthenium(III) ExcitonBlocking Layers. Adv. Mater. 2005, 17, 2714-2718.

(14) Song, Q. L.; Li, F. Y.; Yang, H.; Wu, H. R.; Wang, X. Z.; Zhou, W.; Zhao, J. M.; Ding, X. M.; Huang, C. H.; Hou, X. Y. Smallmolecule organic solar cells with improved stability. Chem. Phys. Lett. 2005, 416, 42-46.

(15) Vogel, M.; Doka, S.; Breyer, C.; Lux-Steiner, M. C.; Fostiropoulos, $\mathrm{K}$. On the function of a bathocuproine buffer layer in organic photovoltaic cells. Appl. Phys. Lett. 2006, 89, No. 163501.

(16) Liu, Y.; Ren, Q.; Su, Z.; Chu, B.; Li, W.; Wu, S.; Jin, F.; Zhao, B.; Yan, X.; Wang, J.; Fan, D.; Zhang, F. The working mechanism of organic photovoltaic cell by using copper phthalocyanine as exciton blocking layer. Org. Electron. 2012, 13, 2156-2159.

(17) Gommans, H.; Verreet, B.; Rand, B. P.; Muller, R.; Poortmans, J.; Heremans, P.; Grenoe, J. On the role of bathcuproine in organic photovoltaic cells. Adv. Funct. Mater. 2008, 18, 3686-3691.

(18) Crispin, X. Interface dipole at organic/metal interfaces and organic solar cells. Sol. Energy Mater. Sol. Cells 2004, 83, 147-168.

(19) Wang, M. L.; Song, Q. L.; Wu, H. R.; Ding, B. F.; Gao, X. D.; Sun, X. Y.; Din, X. M.; Hou, X. Y. Small-molecular organic solar cells with C60/Al composite anode. Org. Electron. 2007, 8, 445-449.

(20) Steindamm, A.; Brendel, M.; Topczak, A. K.; Pflaum, J. Thickness dependent effects of an intermediate molecular blocking layer on the optoelectronic characteristics of organic bilayer photovoltaic cells. Appl. Phys. Lett. 2012, 101, No. 143302.

(21) Chandran, H. T.; Qing, J.; Zhang, H.; Chan, C.-Y.; Ng, T.-W.; Lo, M.-F.; Lee, C.-S. Effects of idling time between depositions of organic layers and metal electrode in organic photovolraic device. Org. Electron. 2015, 26, 99-103.

(22) Peumans, P.; Forrest, S. R. Very-high-efficiency doubleheterostructure copper phthalocyanine/C60 photovoltaic cells. Appl. Phys. Lett. 2001, 79, 126-128.

(23) Yu, J.; Wang, N.; Zang, Y.; Jiang, Y. Organic photovoltaic cells based on TPBi as cathode buffer layer. Sol. Energy Mater. Sol. Cells 2011, 95, 664-668.

(24) Wu, H. R.; Song, Q. L.; Wang, M. L.; Li, F. Y.; Hang, H.; Wu, Y.; Huang, C. H.; Ming, D. X.; Hou, X. Y. Stable small-molecule organic solar cells with 1,3,5-(2-N-phenylbenzimidazolyl) benzene as an organic buffer. Thin Solid Films 2007, 515, 8050-8053.

(25) Lee, J.; Park, S.; Lee, Y.; Kim, H.; Shin, D.; Jeong, J.; Jeong, K.; Cho, S. W.; Lee, H.; Yi, Y. Electron transport mechanism of bathocuproine exciton blocking layer in organic photovoltaic. Phys. Chem. Chem. Phys. 2016, 18, 5444-5452.

(26) Yin, X.; Han, J.; Zhou, Y.; Gu, Y.; Tai, M.; Nan, H.; Zhou, Y.; $\mathrm{Li}$, J.; Lin, H. Critical roles of potassium in charge-carrier balance and diffusion induced defect passivation for efficient inverted perovskite solar cells. J. Mater. Chem. A 2019, 7, 5666-5676.

(27) Morsli, M.; Bernède, J. C.; Cattin, L.; Dahou, F.; Khelil, A. On the Exciton blocking layer et the interface organic/cathode in multiheterojunction organic solar cells. Energy Procedia 2012, 31, 7480.

(28) Reese, M. O.; Gevorgyan, S. A.; Jørgensen, M.; Bundgaard, E.; Kurtz, S. R.; Ginley, D. S.; Olson, D. C.; Lloyd, M. T.; Morvillo, P.; 
Katz, E. A.; Elschner, A.; Haillant, O.; Currier, T. R.; Shrotriya, Vi.; Hermenau, M.; Riede, M.; Kirov, K. R.; Trimmel, G.; Rath, T.; Ingänas, O.; Zhang, F.; Andersson, M.; Tvingstedt, K.; Lira-Cantu, M.; Laird, D.; McGuiness, C.; Gowrisanker, S. J.; Pannone, M.; Xiao, M.; Hauch, J.; Steim, R.; Longchamp, D. M. De.; Rösch, R.; Hoppe, H.; Espinosa, N.; Urbina, A.; Yaman- Uzunoglu, G.; Bonekamp, J.-B.; van Breemen, A. J. J. M.; Girotto, C.; Voroshazi, E.; Krebs, F. C. Consensus stability testing protocols for organic photovoltaic materials and devices. Sol. Energy Mater. Sol. Cells 2011, 95, 12531267.

(29) Dennler, G.; Lungenschmied, C.; Neugebauer, H.; Sariciftci, N. S.; Latrèche, M.; Czeremuszkin, G.; Wertheimer, M. R. A new encapsulation solution for flexible organic solarcells. Thin Solid Films 2006, 511-512, 349-353.

(30) Zhang, D.; Li, Y.; Zhang, G.; Gao, Y.; Duan, L.; Wang, L.; Qiu, Y. Lithium cobalt oxide as electron injection material for high performance organic ligth-emitting diodes. Appl. Phys. Lett. 2008, 92, No. 263303.

(31) Cho, K.; Cho, S. W.; Whang, C.-N.; Jeong, K.; Kang, S. J.; Yi, Y. Photoemission study of the electronic structures of tris-(8hydroxyquinoline) aluminum/Li2O/Al interfaces. Appl. Phys. Lett. 2007, 91, No. 122101.

(32) Yang, L.; Xu, H.; Tian, H.; Yin, S.; Zhang, F. Effect of cathode buffer layer on the stability of polymer bulk heterojunction solar cells. Sol. Energy Mater. Sol. Cells 2010, 94, 1831-1834.

(33) Mott, N. F.; Gurney, R. W. Electronic Processes in Ionic Crystals, 2nd ed.; Oxford University Press: Oxford, 1948.

(34) Tyagi, P.; Srivastava, R.; Kumar, A.; Tuli, S.; Kamalasanan, M. $\mathrm{N}$. Effect of doping of cesium carbonate on electron transport transport in this(8-hydroxyquinolinato) aluminum. Org. Electron. 2013, 14, 1391-1395.

(35) Sakurai, Y.; Hosoi, Y.; Ishii, H.; Ouchi, Y.; Salvan, G.; Kobitski, A.; Kampen, T. U.; Zahn, D. R. T.; Seki, K. Study of the interaction of tris-(8-hydroxyquinoline) aluminum (Alq3) with potassium using vibrational spectroscopy: Examination of possible isomerization upon K doping. J. Appl. Phys. 2004, 96, 5534.

(36) Schwieger, T.; Peisert, H.; Knupfer, M.; Golden, M. S.; Fink, J. Electronic structure of K-intercalated 8-tris-hydroxyquinoline aluminum studied by photoemission spectroscopy. Phys. Rev. B 2001, 63, No. 165104

(37) Kim, H. S.; Lee, H.; Jeon, P. E.; Jeong, K.; Lee, J. H.; Yi, Y. Revised hole injection mechanism of a thin LiF layer introduced between pentacene and an indium tin oxide anode. J. Appl. Phys. 2010, 108, No. 053701.

(38) Mason, M. G.; Tang, C. W.; Hung, L.-S.; Raychaudhuri, P.; Madathil, J.; Giesen, D. J.; Yan, L.; Le, Q. T.; Gao, Y.; Lee, S.-T.; Liao, L. S.; Cheng, L. F.; Salaneck, W. R.; dos Santos, D. A.; Bredas, J. L. Interfacial chemistry of $\mathrm{Alq}_{3}$ and $\mathrm{LiF}$ with reactive metals. J. Appl. Phys. 2001, 89, 2756-2765.

(39) Lee, J.; Lee, H.; Jeon, P.; Jeong, K.; Kim, T. G.; Kim, J. W.; Yi, $\mathrm{Y}$. Direct evidence of $\mathrm{n}$-type dopind in organic light-emitting devices: N free Cs doping of CsN3. Appl. Phys. Lett. 2012, 100, No. 203301.

(40) Wang, F.; Xiong, T.; Qiao, X.; Ma, D. Origin of improvement in device performance via the modification role od cesium hydroxide doped tris(8-hydroxyquinoline) aluminum interfacial layer on ITO in inverted bottom emission light emitting diodes. Org. Eectron. 2009, 10, 266-274.

(41) Tress, W.; Petrich, A.; Hummert, M.; Hein, M.; Leo, K.; Riede, M. Imbalanced mobilities causing S-shaped IV curves in planar heterojunction organic solar cells. Appl. Phys. Lett. 2011, 98, No. 063301.

(42) Wagenpfahl, A.; Rauh, D.; Binder, M.; Deibel, C.; Dyakonov, V. $S$-shapped current-voltage characteristics of organic solar devices. Phys. Rev. B 2010, 82, No. 115306.

(43) Sims, L.; Hörmann, U.; Hanfland, R.; MacKenzic, R. C. I.; Kogler, F. R.; Steim, R.; Brütting, W.; Schilinsky, P. Investigation of the $\mathrm{S}$-shape caused by hole selective layer in bulk heterojunction solar cells. Org. Electron. 2014, 15, 2862-2867.
(44) Lare, Y.; Kouskoussa, B.; Benchouk, K.; Djobo, S. O.; Cattin, L.; Morsli, M.; Diaz, F. R.; Gacitua, M.; Abachi, T.; del Valle, M.A.; Amijo, F.; East, G. A.; Bernède, J. C. Influence of the exciton blocking layer on the stability of layered organic solar cells. J. Phys. Chem. Solids 2011, 72, 97-103. 